\title{
Penemuan Zon Himpunan Pseudoalbaillella globosa (Radiolaria) di Pos Blau, Baratdaya Kelantan, Semenanjung Malaysia dan Implikasinya terhadap Biostratigrafi Radiolaria
}

(Discovery of Pseudoalbaillella globosa Assemblage Zone (Radiolaria) from Pos Blau, Southwest Kelantan, Peninsular Malaysia and its Implication on the Radiolarian Biostratigraphy)

\author{
Muhammad Ashahadi DzulKafli*, Mohd Shafeea Leman \& KHOR Wei Chung
}

\author{
ABSTRAK
}

Fosil radiolaria yang terawet dengan agak baik telah ditemui di dalam lapisan rijang yang tersingkap di km 38 , lebuhraya Gua Musang-Cameron Highland, berdekatan dengan Pos Blau, baratdaya Kelantan, Semenanjung Malaysia. Sebanyak 20 spesies fosil radiolaria telah dikenal pasti. Spesies ini mewakili zon himpunan Pseudoalbaillella globosa yang menunjukkan usia (Roadian) Awal Perm Tengah. Zon himpunan radiolaria ini merupakan rekod biostratigrafi yang baru untuk jujukan batuan bersilika di Pos Blau dan di dalam Zon Sutura Bentong-Raub.

Kata kunci: Kelantan; Pos Blau; Radiolaria; (Roadian) Awal Perm Tengah; Semenanjung Malaysia

ABSTRACT

A quite well preserved radiolarian fossils were discovered from bedded chert outcropped at km 38, of the Gua MusangCameron Highland highway, near Pos Blau, southwest Kelantan, Peninsular Malaysia. A total of 20 species of radiolarian fossils were identified. These species represent the Pseudoalbaillella globosa Assemblage Zone of (Roadian) Early Middle Permian age. This radiolarian assemblage zone is a new biostratigraphy record for the siliceous rocks succession at Pos Blau and also in the Bentong-Raub Suture Zone.

Keywords: Kelantan; Peninsular Malaysia; Pos Blau; Radiolarian; (Roadian) Early Middle Permian

\section{PENDAHULUAN}

Batuan berkomposisi silika seperti rijang, batu lumpur bersilika dan syal bersilika tersingkap di beberapa lokaliti dalam beberapa formasi batuan di Semenanjung Malaysia. Menurut Basir (2003), batuan berijang di Semenanjung Malaysia mempunyai julat usia dari Silur, Devon Akhir hingga Karbon Awal dan Perm Awal hingga Trias Tengah. Walau bagaimanapun, fosil radiolaria tertua yang dilaporkan di Semenanjung Malaysia adalah berusia Devon Akhir (Famennian) dan yang paling muda disahkan berusia Trias Tengah (Karnian Akhir-Norian Tengah).

Fosil radiolaria berusia Perm telah banyak ditemui di dalam batuan Jalur Barat, Zon Sutura Bentong-Raub dan Jalur Tengah Semenanjung Malaysia. Di Jalur Barat, fosil radiolaria berusia Perm telah ditemui dalam batuan Formasi Semanggol (Basir 2008, 1997, 1994; Basir et al. 2005; Sashida et al. 1995; Spiller 2002; Spiller \& Metcalfe 1995a) dan Formasi Gerik (Mat Niza et al. 2012; The Malaysia-Thai Working Group 2014). Dalam Zon Sutura Bentong-Raub juga telah dilaporkan beberapa penemuan fosil radiolaria. Antaranya di Bentong (Spiller 2002), Karak (Spiller 2002; Spiller \& Metcalfe 1995a,1995b), Pos Blau (Basir 1994; Basir \& Che Aziz 1997; Basir et al. 2013; Muhammad Ashahadi et al. 2016, 2012; Spiller 2002; Spiller \& Metcalfe 1995b) dan Formasi Mangga (The
Malaysia-Thai Working Group 2014). Dalam Jalur Timur Semenanjung Malaysia pula, hanya satu rekod penemuan fosil radiolaria dilaporkan iaitu di Genting Serampang, Jengka (Basir et al. 1995). Kesemua fosil radiolaria ini telah dimasukkan ke dalam zon himpunan radiolaria tertentu dan merekodkan maklumat biostratigrafi jujukan rijang dan batuan bersilika berusia Perm yang hampir lengkap di negara ini.

Satu kajian telah dijalankan ke atas sebuah singkapan rijang yang terletak berdekatan dengan Pos Blau. Jujukan batuan ini masih segar dan membolehkan kajian terhadap fosil radiolaria dilakukan bagi tujuan penentuan usia dan korelasi biostratigrafi. Jujukan ini telah dicerap litologinya dan sebuah log sedimen telah dibina. Sampel rijang telah diambil untuk diproses bagi mendapatkan fosil radiolaria. Kertas ini membentangkan keputusan daripada kerja lapangan dan keputusan kajian fosil radiolaria yang diperoleh daripada singkapan ini dan mengemas kini biostratigrafi radiolaria bagi kawasan kajian dan di dalam Zon Sutura Bentong-Raub, Semenanjung Malaysia.

\section{GEOLOGI KAWASAN DAN SINGKAPAN KAJIAN}

Pos Blau ialah sebuah perkampungan kecil di pinggir Sungai Berok yang terletak dalam daerah Gua Musang 
di baratdaya negeri Kelantan. Kawasan ini bertopografi tinggi dan aktiviti pertanian adalah sangat giat dijalankan. Pembukaan lebuhraya yang menghubungkan bandar Gua Musang di Kelantan dan Cameron Highlands di Pahang telah menampakkan batuan segar di sepanjang laluan ini yang melalui kawasan Pos Blau.

Aw (1974) mengelaskan batuan di sekitar kawasan ini sebagai jujukan batuan sedimen piroklastik. Mohd Shafeea (1995) menyatakan batuan di Pos Blau dan Kuala Betis terdiri daripada batuan berusia Perm hingga Trias dan meletakkan batuan di sini sebagai sebahagian daripada formasi Gua Musang. Pelbagai jenis fosil telah direkodkan dari sekitar kawasan Pos Blau dan ditemui di dalam pelbagai jenis batuan seperti rijang, batu lumpur dan batu kapur. Fosil tersebut termasuklah fosil tumbuhan, fosil batang kayu tersilika, ammonoid, gastropod, bryozoa, krinoid, bivalvia, alga, forminifera dan radiolaria. Fosil ini menunjukkan batuan di sekitar Pos Blau berjulat usia dari Karbon (Umar Hamzah \& Ng 1995) hingga Trias Akhir (Fontaine et al. 1995; Ibrahim Amnan \& Fontaine 1996). Tjia dan Syed Sheikh (1996) telah mentafsirkan jujukan batuan di sepanjang jalan dari Kampung Raja, Cameron Highlands hingga ke Pos Blau sebagai sebahagian daripada kompleks akresi yang membentuk Zon Sutura Bentong-Raub. Menurut mereka, sempadan timur bagi zon sutura ini terletak di barat Pos Blau yang diwakili oleh lapisan rijang yang tersungkup dan dipisahkan oleh unit olistostrom di bahagian baratnya. Namun begitu, sentuhan di antara formasi Gua Musang dengan Sutura BentongRaub masih menjadi persoalan sehingga ke hari ini.

Singkapan kajian terletak pada kedudukan $\left(4^{\circ} 45^{\prime} 09.70^{\prime \prime} \mathrm{U}, 101^{\circ} 45^{\prime} 28.46^{\prime \prime} \mathrm{T}\right)$, kira-kira $500 \mathrm{~m}$ di timur jambatan Sungai Berok berhampiran km 38 lebuhraya Gua Musang-Cameron Highland, Pos Blau, baratdaya Kelantan (Rajah 1). Singkapan ini dilabel sebagai singkapan PB-2 (PB merujuk kepada Pos Blau) dan terdiri daripada selanglapis rijang dengan batu lumpur bertuf (Rajah 2). Tebal keseluruhan jujukan ini ialah 6 m. Rijang berwarna merah keperangan dan kelabu cerah. Tebal lapisan individunya berjulat antara 2-14 cm. Batu lumpur bertuf pula berwarna perang gelap hingga perang dengan ketebalan daripada 4 hingga $40 \mathrm{~cm}$. Sebanyak 13 sampel rijang diambil secara sistematik mewakili keseluruhan ketebalan rijang.

\section{BAHAN DAN KAEDAH}

Sebanyak 13 sampel telah diambil dan dilabel sebagai sampel G1 hingga G13 dalam jujukan memuda ke atas. Kaedah piawai untuk mengekstrak fosil radiolaria daripada rijang menggunakan asid hidroflorik, HF seperti yang diperkenalkan oleh Pessagno Jr. dan Newport (1972) telah dijalankan. Sampel dipecah menjadi serpih kecil berdimensi $1 \times 1 \mathrm{~cm}$. Sampel kemudiannya direndam di dalam larutan HF berkepekatan $49 \%$ yang dicairkan selama 5 hari. Seterusnya sampel dicuci menggunakan air biasa, dituras dan baki turasan dikeringkan dalam masa 4 hingga 5 hari. Proses ini dijalankan sebanyak dua kali. Baki turasan yang kering diperiksa kandungannya menggunakan mikroskop binokular. Semua spesimen fosil radiolaria yang ditemui diambil menggunakan berus halus dan foto spesimen terpilih diambil menggunakan Mikroskop Imbasan Elekron (SEM).

\section{ZON HIMPUNAN DAN USIA RADIOLARIA}

Radiolaria telah diekstrak daripada rijang dan hasil analisis mendapati spesimen ini terawet dengan agak baik dan spesimen ini boleh dikenal pasti hingga ke tahap spesies. Daripada 13 sampel, hanya 11 daripadanya mengandungi radiolaria. Taburan spesies yang ditemui adalah seperti dalam Rajah 3. Fosil radiolaria tidak ditemui dalam sampel G2 dan G3.

Sebanyak 20 spesies radiolaria telah dikenal pasti. Kesemuanya tergolong dalam 8 famili dan 11 genera. Spesies tersebut ialah Pseudoalbaillella postscalprata Ishiga (Rajah 5-1), Pseudoalbaillella ornata Ishiga \& Imoto (S-Type) (Rajah 5-2), Pseudoalbaillella cf. elongata Ishiga \& Imoto (Rajah 5-3), Pseudoalbaillella longtanensis Sheng \& Wang (Rajah 5-4,5), Pseudoalbaillella sp. aff. Pseudoalbaillella longicornis Ishiga \& Imoto (Rajah 5-7), Pseudoalbaillella fusiformis (Holdsworth \& Jones) (Rajah 5-9), Pseudoalbaillella globosa Ishiga dan Imoto (Rajah 5-12), Hegleria mammilla (Sheng \& Wang) (Rajah 5-13), Hegleria sp. A (Rajah 5-14), Latentifistula crux Nazarov \& Ormiston (Rajah 5-15), Latentifistula texana Nazarov \& Ormiston (Rajah 5-16), Latentifistula sp. A (Rajah 5-17), Latentibifistula asperspongiosa Sashida \& Tonishi (Rajah 5-18), Pseudotormentus kamigoriensis De Wever \& Caridroit (Rajah 5-19), Deflandrella sp. (Rajah 5-20), Ishigaum trifustis De Wever \& Caridroit (Rajah 5-21), Copielintra orbiculata Nestell \& Nestell (Rajah 5-22), Quadricaulis inflata (Sashida \& Tonishi) (Rajah 5-23), Copicyntra sp. (Rajah 5-24) dan Stigmosphaerostylus sp. (Rajah 5-25). Kesemua 7 spesies daripada genus Pseudoalbaillella telah pun diperihalkan oleh Muhammad Ashahadi et al. (2016), manakala sistematik taksonomi bagi spesies yang lain sedang dalam peringkat penulisan.

Kelimpahan radiolaria di bahagian bawah jujukan adalah sangat rendah. Bahagian tengah jujukan mempunyai kelimpahan radiolaria yang tinggi manakala di bahagian atas jujukan, kelimpahan radiolaria adalah sederhana. Kelimpahan radiolaria yang tinggi di bahagian tengah jujukan disumbang oleh spesies Hegleria mammilla (Sheng \& Wang) dan Copielintra orbiculata Nestell \& Nestell. Dua spesies ini sangat dominan terutama di dalam sampel G6. Sebanyak 7 spesies daripada genus Pseudoalbaillella telah dikenal pasti dan huraian taksonomi bagi genus ini telah disediakan dalam Muhammad Ashahadi et al. (2016). Spesies Pseudoalbaillella fusiformis (Holdsworth \& Jones) muncul buat pertama kali dalam sampel G1 dan ditemui dalam sampel berikutnya iaitu sampel G4, G9, G11 dan G12. Pseudoalbaillella longtanensis Sheng \& Wang mula muncul dalam sampel G4 dan juga ditemui dalam sampel G6, G8, G9 dan G11. Pseudoalbaillella globosa Ishiga \& Imoto muncul buat pertama kali dalam 


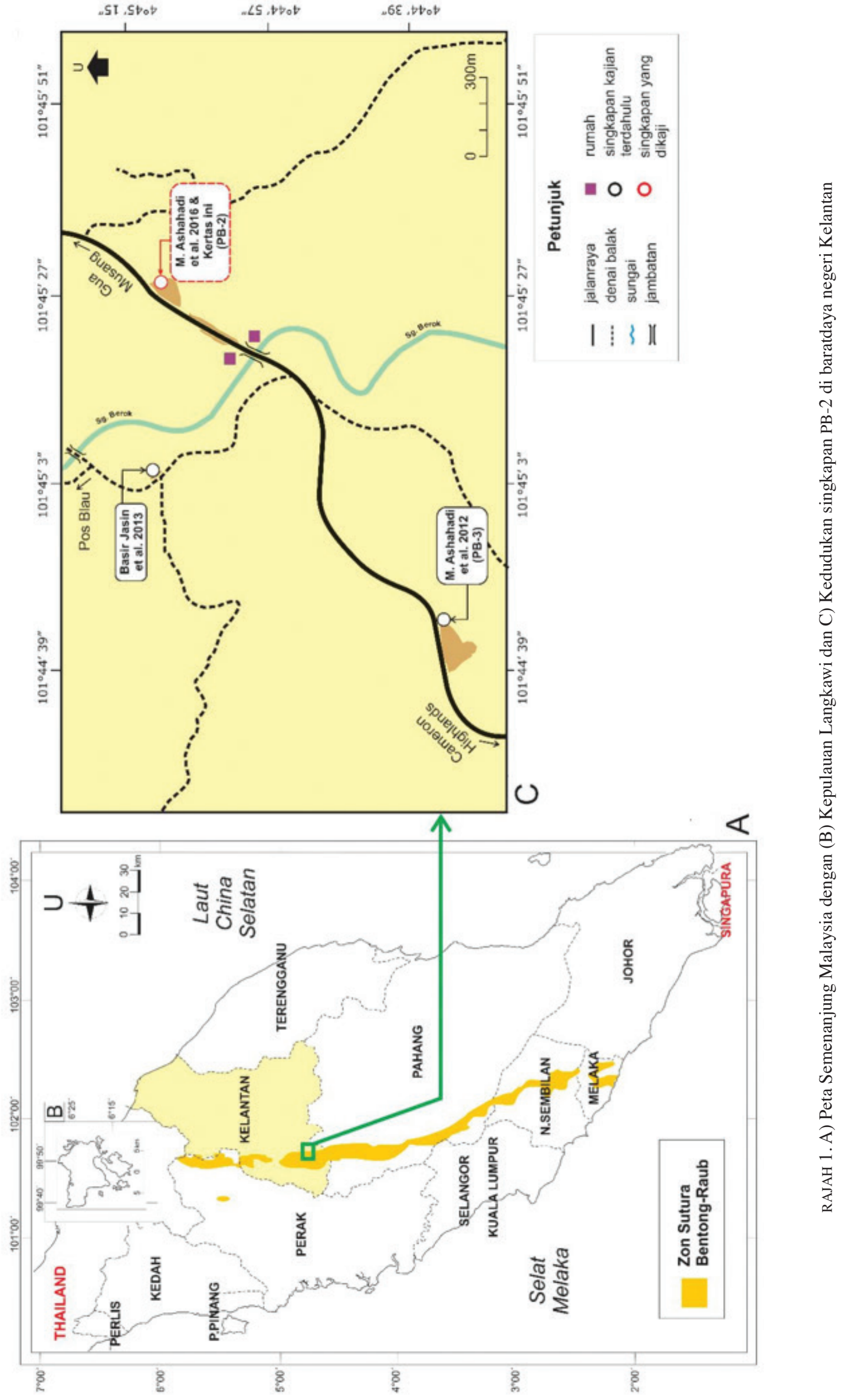



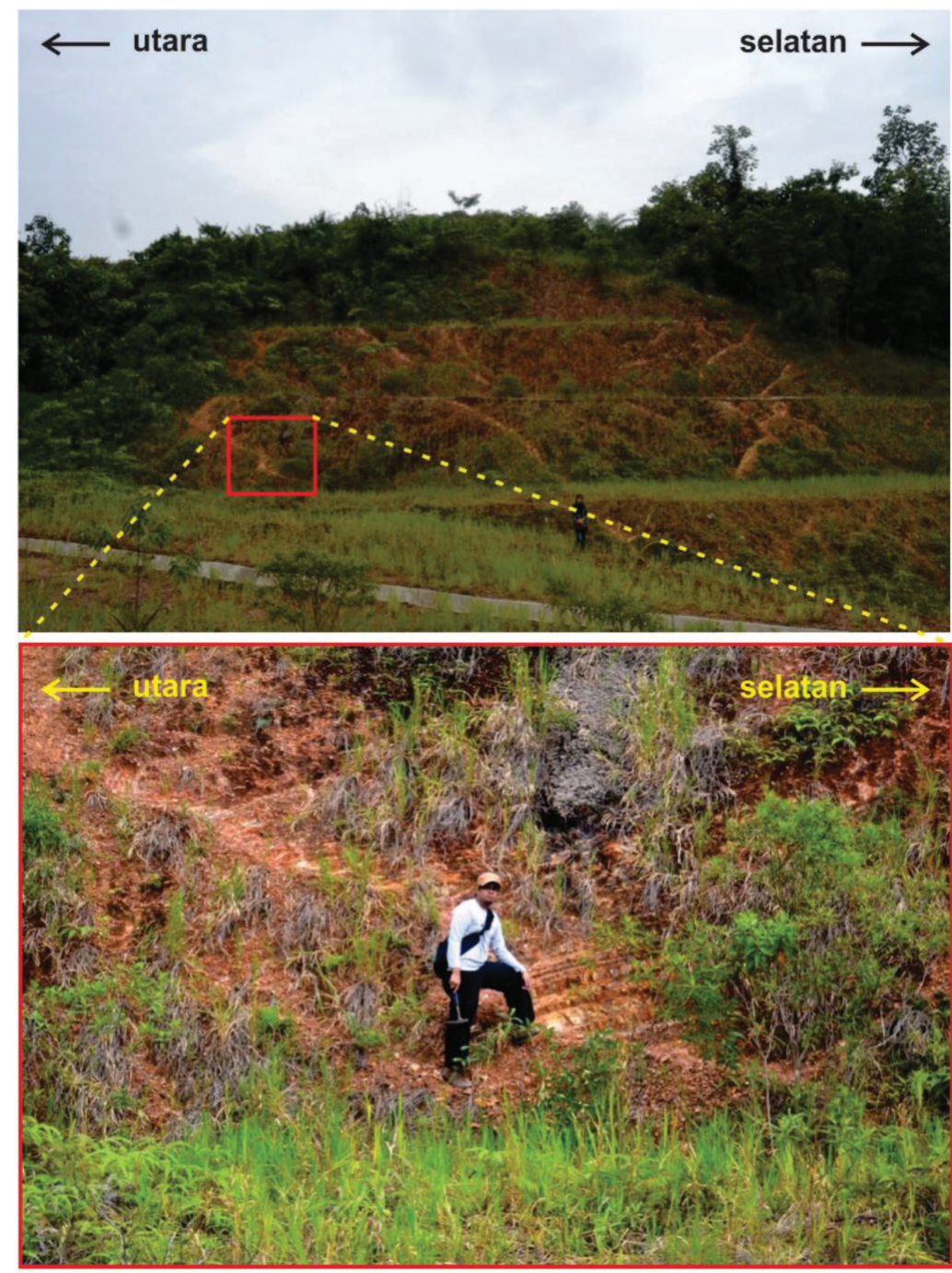

RAJAH 2. Singkapan PB-2 rijang berselanglapis dengan batu lumpur bertuf di timur Pos Blau (Muhammad Ashahadi et al. 2016))

sampel G6 dan kemudian di dalam sampel G7, G11 dan G12. Pseudoalbaillella sp. aff. Pseudoalbaillella longicornis Ishiga \& Imoto hadir dalam sampel G4, G5, G6, G7, G8, G10, G11 dan G12.

Beberapa spesies indeks yang mewakili usia Perm Awal juga ditemui di dalam jujukan rijang ini. Spesies tersebut ialah Pseudoalbaillella scalprata m. postscalprata Ishiga, Pseudoalbaillella ornata Ishiga \& Imoto (Jenis-S) dan Pseudoalbaillella cf. elongata Ishiga Imoto. Ketigatiga spesies ini adalah spesies penunjuk kepada usia (Sakmarian) Perm Awal (Ishiga 1990). Spesimen tunggal Pseudoalbaillella ornata Ishiga \& Imoto (Jenis-S) muncul pertama kali dalam sampel G12. Spesies berjulat pendek ini menjadi indikator kepada Zon Himpunan Pseudoalbaillella lomentaria (Ishiga 1990) yang mewakili usia Sakmarian Awal. Pseudoalbaillella scalprata postscalprata Ishiga pula ditemui dalam sampel G4, G5, G6, G8, G10, G11 dan G12. Spesies tunggal Pseudoalbaillella cf. elongata Ishiga \& Imoto pula adalah spesies indeks berjulat usia pendek yang menjadi penunjuk kepada Zon Himpunan Pseudoalbaillella scalprata m. rhombothoracata (Ishiga 1990) dan mewakili usia Sakmarian Akhir. Spesies ini ditemui dalam sampel G6.

Sepuluh spesies daripada order Latentifistularia telah dikenal pasti. Semua spesies tersebut, Deflandrella sp. dan Ishigaum trifustis De Wever dan Caridroit merupakan spesies tunggal yang ditemui dalam kajian ini. Keduaduanya hadir dalam sampel G6. Spesies ini lazim ditemui di dalam himpunan radiolaria berusia Perm Akhir (Sashida \& Salyapongse 2002; Sashida \& Tonishi 1986; Sashida et al. 1995; Yao \& Kuwahara 2000). Hegleria mammilla (Sheng \& Wang) dominan dalam sampel G6 dan sebanyak 74 spesimen telah ditemui dalam sampel ini.

Berdasarkan kehadiran spesies Pseudoalbaillella globosa Ishiga \& Imoto, Pseudoalbaillella fusiformis (Holdsworth \& Jones), Pseudoalbaillella longtanensis Sheng \& Wang dan Pseudoalbaillella sp. aff. Pseudoalbaillella longicornis Ishiga \& Imoto bersama-sama Hegleria mammilla (Sheng \& Wang), jujukan rijang yang dikaji sesuai dimasukkan ke dalam Zon Himpunan Pseudoalbaillella globosa yang mewakili usia Roadian, Awal Perm Tengah. 


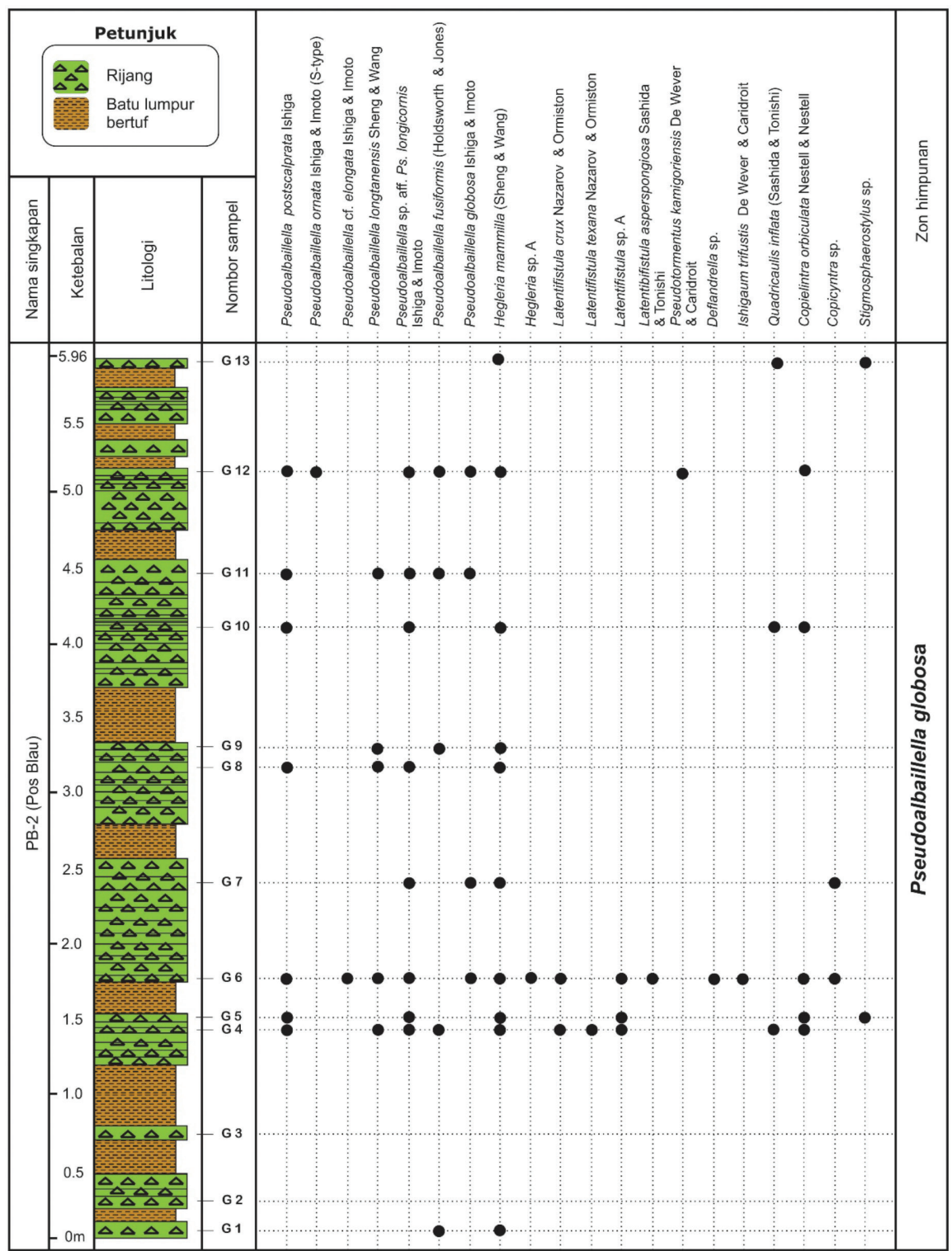

RAJAH 3. Turus log sedimen dan taburan fosil radiolaria di singkapan PB-2

\section{PERBINCANGAN}

\section{SEKUTUAN BATUAN DAN SEKITARAN PENGENDAPAN}

Rijang beradiolaria di singkapan (РB-2) didapati berselanglapis dengan batu lumpur bertuf. Jujukan sebegini dikategorikan sebagai sekutuan rijang dan volkano bersilika. Jujukan rijang sebegini menunjukkan sekitaran tektonik di kawasan lembangan dekat arka kepulauan (Jones \& Murchey 1986) atau di lembangan rekahan di sepanjang pinggir benua (Karl 1989). Jujukan rijang yang berselanglapis dengan batu lumpur bertuf juga telah dilaporkan oleh Basir et al. (1995) di Jengka, Pahang. Situasi ini membuktikan bahawa kegiatan volkano bersilika di Jalur Tengah Semenanjung Malaysia telah bermula sejak dari Perm Tengah dan berterusan hingga Trias Tengah (Basir 2003).

\section{BIOSTRATIGRAFI}

Pada peringkat antarabangsa, zon himpunan dalam kajian ini boleh dikorelasikan dengan Zon Himpunan Pseudoalbaillella globosa (Ishiga 1990) di baratdaya Jepun dan Zon Himpunan Pseudoalbaillella globosa (Wang \& Yang 2011) di Selatan China. Zhang et al. (2010) melaporkan kemunculan pertama kali fosil konodon Jinogondolella nankingensis gracilis di bahagian bawah Zon Himpunan Pseudoalbaillella globosa yang ditemui di dalam lapisan rijang di Dachongling, Guangxi, Selatan China. Jinogondolella nankingensis gracilis adalah fosil konodon yang digunakan sebagai spesies indeks dalam penentuan sempadan bawah bagi Siri Guadalupian (sempadan di antara Kungurian dan Roadian). Zon Himpunan ini menunjukkan usia Roadian (Awal Perm Tengah).

Fosil radiolaria Pos Blau telah dilaporkan pertama kali oleh Basir (1994). Beliau menemui fosil radiolaria 
berusia Perm Awal dalam selanglapis rijang dengan batu lumpur. Kajian tersebut diperincikan lagi oleh Basir dan Che Aziz (1997) dan sebanyak 22 spesies radiolaria daripada Zon himpunan Pseudoalbaillella lomentaria telah direkodkan. Spiller (2002) dan Spiller dan Metcalfe (1995b) juga melaporkan penemuan radiolaria Perm Awal (Wolfcampian) daripada dua lokasi persampelan iaitu CH13 dan CH14. Sampel daripada CH13 diwakili oleh Zon himpunan Pseudoalbaillella lomentaria dan Zon himpunan Pseudoalbaillella scalprata $\mathrm{m}$. rhombothoracata manakala sampel daripada CH14 mewakili zon Pseudoalbaillella longtanensis namun kedudukan singkapan kajian mereka tidak dapat dikesan secara tepat.

Kajian lanjut terhadap jujukan rijang dan batuan bersilika di Pos Blau diteruskan oleh Muhammad Ashahadi et al. (2012). Dalam kajian tersebut, mereka telah mengkaji jujukan selanglapis rijang dengan syal yang terletak kira-kira $2 \mathrm{~km}$ daripada singkapan kajian ini dan dilabelkan sebagai singkapan PB-3. Dua zon himpunan dikenal pasti iaitu Zon Himpunan Pseudoalbaillella lomentaria (Sakmarian awal) dan Zon Himpunan Pseudoalbaillella scalprata m.rhombothoracata mewakili usia Sakmarian akhir. Setahun kemudian, Basir et al. (2013) pula melaporkan penemuan fosil radiolaria di sebuah singkapan yang terletak kira-kira $600 \mathrm{~m}$ ke arah baratlaut dari jambatan Sungai Berok. Menurut mereka, sebanyak 14 spesies radiolaria telah ditemui dalam batu lumpur bersilika dan fosil ini dimasukkan ke dalam Zon
Himpunan Pseudoalbaillella fusiformis (Roadian akhir) dan Zon Himpunan Follicucullus monacanthus (Wordian) dengan masing-masing menunjukkan usia Perm Tengah. Merujuk kepada maklumat terdahulu, kajian radiolaria dalam rijang dan batu lumpur bersilika di Pos Blau belum pernah merekodkan penemuan fosil radiolaria daripada zon himpunan Pseudoalbaillella globosa. Maka, kertas ini penting dalam memperkenalkan buat pertama kalinya zon himpunan Pseudoalbaillella globosa di kawasan baratdaya Kelantan khususnya di Pos Blau. Kemaskini data biostratigrafi radiolaria dalam jujukan rijang dan batuan bersilika di Pos Blau ditunjukkan seperti dalam Rajah 4. Merujuk pada Rajah 4, dapat dilihat bahawa usia fosil radiolaria di Pos Blau berjulat seawal Perm Awal (Sakmarian) hingga Perm Tengah (Wordian). Namun begitu usia ini tidaklah berterusan kerana setakat ini masih belum lagi ditemui zon himpunan Albaillella sinuata yang mewakili usia Artinskian di Pos Blau. Berdasarkan kajian kepustakaan, hanya satu sahaja zon himpunan Albailella sinuata pernah dilaporkan di Semenanjung Malaysia. Spiller dan Metcalfe (2002) merekodkan penemuan zon himpunan ini daripada singkapan KLK2 yang terletak di Kampung Cinta Manis berdekatan Karak, Pahang. Usaha untuk mengisi rumpang usia ini akan diteruskan terhadap beberapa singkapan lain yang terdapat di sekitar Pos Blau dalam kajian lanjut.

Seperti yang dinyatakan dalam Tjia dan Syed Sheikh (1996), Pos Blau adalah sempadan timur bagi Zon Sutura

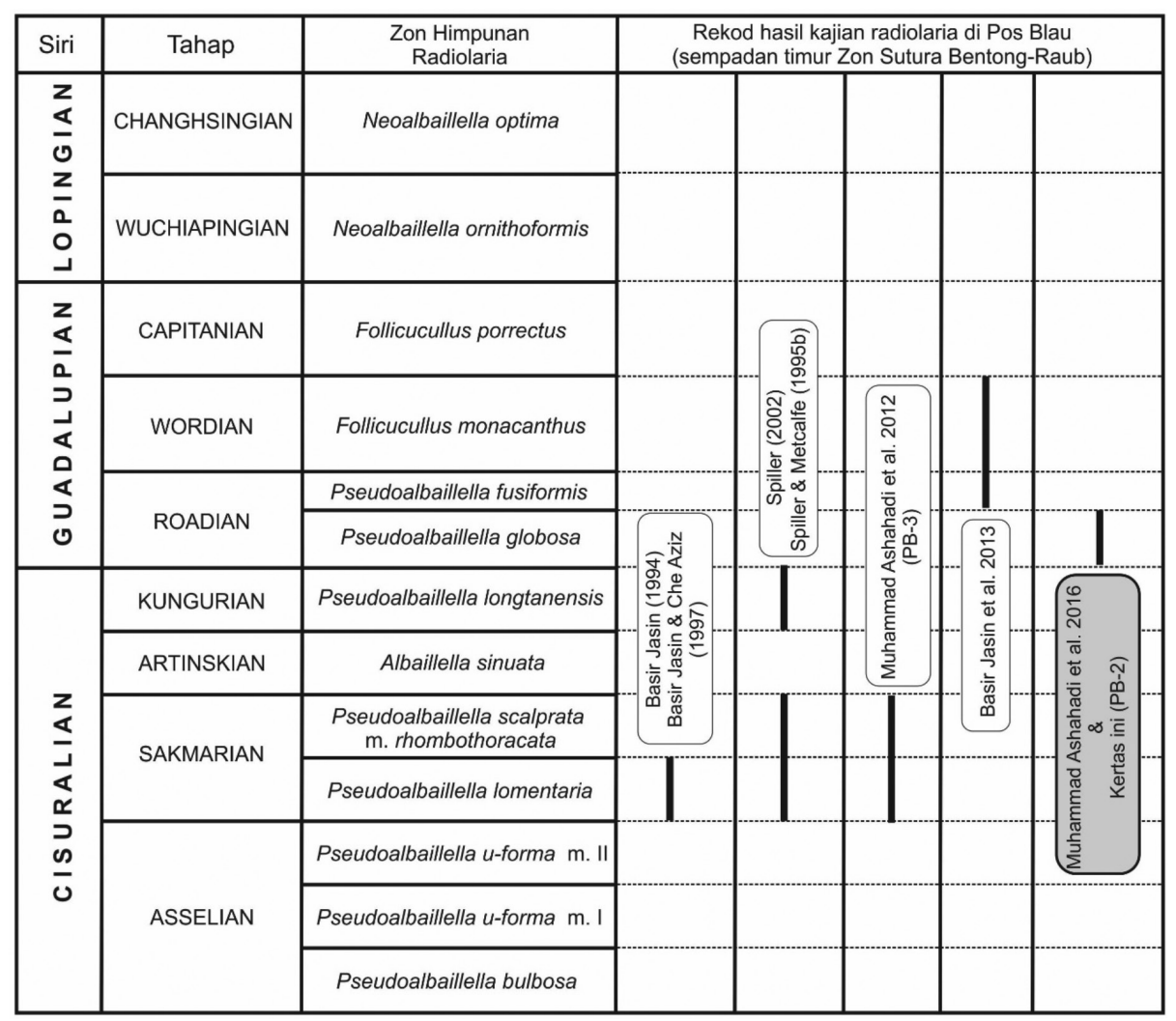

RAJAH 4. Carta biostratigrafi radiolaria di kawasan Pos Blau, baratdaya Kelantan. Zon himpunan radiolaria dibina berdasarkan Ishiga (1990), Kuwahara et al. (1998), Zhang et al. (2010) dan Basir \& Zaiton (2011) 




RAJAH 5. 1-Pseudoalbaillella scalprata postscalprata Ishiga, 2-Pseudoalbaillella ornata Ishiga \& Imoto (S-Type), 3-Pseudoalbaillella $\mathrm{cf}$. elongata Ishiga \& Imoto, 4-5-Pseudoalbaillella longtanensis Sheng \& Wang, 6-7-Pseudoalbaillella sp. aff. Pseudoalbaillella longicornis Ishiga \& Imoto, 8-9-Pseudoalbaillella fusiformis (Holdsworth \& Jones), 10-12Pseudoalbaillella globosa Ishiga \& Imoto, 13-Hegleria mammilla (Sheng \& Wang), 14-Hegleria sp. A, 15-Latentifistula crux Nazarov \& Ormiston, 16-Latentifistula texana Nazarov \& Ormiston, 17-Latentifistula sp. A, 18-Latentibifistula asperspongiosa Sashida \& Tonishi, 19-Pseudotormentus kamigoriensis De Wever \& Caridroit, 20-Deflandrella sp., 21-Ishigaum trifustis De Wever \& Caridroit, 22-Quadricaulis inflata (Sashida \& Tonishi), 23-Copielintra orbiculata Nestell \& Nestell, 24-Copicyntra sp., 25-Stigmosphaerostylus sp. 
Bentong-Raub, oleh itu Zon Himpunan Pseudoalbaillella globosa yang baru ditemukan ini juga mencatatkan rekod keputusan yang baru bagi zon himpunan radiolaria dalam Zon Sutura Bentong-Raub di Semenanjung Malaysia.

\section{KESIMPULAN}

Singkapan kajian ini terdiri daripada selanglapis rijang dengan batu lumpur bertuf. Rijang dicirikan oleh warna merah keperangan hingga kelabu cerah. Sebanyak 20 spesies radiolaria telah dikenal pasti tergolong dalam 8 famili dan 11 genera. Komposisi radiolaria ini sesuai dimasukkan ke dalam Zon Himpunan Pseudoalbaillella globosa yang spesifiknya berusia Roadian, Awal Perm Tengah. Zon himpunan ini adalah rekod penemuan baharu bagi jujukan batuan sedimen bersilika di Pos Blau dan juga di dalam Zon Sutura Bentong-Raub. Penemuan rijang beradiolaria di timur Pos Blau ini menimbulkan persoalan tentang kedudukan sebenar sempadan timur Zon Sutura Bentong-Raub dan kedudukan stratigrafi semua jujukan batuan sedimen bersilika di kawasan ini.

\section{PENGHARGAAN}

Kami ingin merakamkan jutaan terima kasih kepada En. Dzulkafli sekeluarga dan En. Yusof Jidin atas segala sokongan dan bantuan sepanjang kerja lapangan dijalankan. Penyelidikan ini dibiaya melalui dana UKMGUP-PLW-08-11-142 dan UKM-GUP-PLW-08-11-141.

\section{RUJUKAN}

Aw, P.C. 1974. Geology of Sungai Nenggiri - Sungai Betis Area, Sheet 44. Geological Survey Malaysia Annual Report 1974: 115-119.

Basir Jasin. 2008. Some Permian radiolarians from Bukit Yoi, Pokok Sena, Kedah. Bulletin of the Geological Society of Malaysia 54: 53-58.

Basir Jasin. 2003. Rijang Beradiolaria Perakam Sejarah Tabii Malaysia. Bangi: Penerbit Universiti Kebangsaan Malaysia.

Basir Jasin. 1997. Permo-Triassic radiolarian from the Semanggol Formation, northwest Peninsular Malaysia. Journal of Asian Earth Sciences 15(1): 43-53.

Basir Jasin. 1996. Discovery of Early Permian radiolaria from the Semanggol Formation, northwest Peninsular Malaysia. Warta Geologi 22(4): 283-287.

Basir Jasin. 1994. Early Permian radiolaria from Ulu Kelantan, Malaysia. Seminar on Permo-Triassic of Peninsular Malaysia and associated mineralization-Abstract of paper. Warta Geologi 20(2): 96.

Basir Jasin \& Zaiton Harun. 2011. Radiolarian Biostratigraphy of Peninsular Malaysia- An update. Bulletin of the Geological Society of Malaysia 57: 27-38.

Basir Jasin \& Che Aziz Ali. 1997. Lower Permian Radiolaria from the Pos Blau area, Ulu Kelantan Malaysia. Journal of Asian Earth Sciences 15(4/5): 327-339.

Basir Jasin, Atilia Bashardin \& Zaiton Harun. 2013. Middle Permian Radiolarian from the siliceous mudstone block near Pos Blau, Ulu Kelantan and their significance. Bulletin of the Geological Society of Malaysia 59: 33-88.
Basir Jasin, Uyop Said \& Rosmah Abdul Rahman. 1995. Late Middle Permian Radiolaria from Jengka area, central Pahang, Malaysia. Journal of Southeast Asian Earth Sciences 12(1/2): 79-83.

Basir Jasin, Zaiton Harun, Uyop Said \& Sulaiman Saad. 2005. Permian Radiolarian Biostratigraphy of the Semanggol Formation, south Kedah, Peninsular Malaysia. Bulletin of the Geological Society of Malaysia 51: 19-30.

Fontaine, H., Ibrahim, B.A. \& Vu Khuc, D. 1995. Triassic limestones of Southwest Kelantan (East and South of Pos Blau) and North Pahang (Merapoh area), Peninsular Malaysia. Proc. of the IGCP Symposium on Geology of Southeast Asia and adjacent areas. Journal of Geology. Series B 5-6: 16-30.

Ibrahim Amnan \& Fontaine, H. 1996. New Palaeontological data of the limestones in Southwest Kelantan and North Pahang, Peninsular Malaysia. Kertas kerja Seminar on Marine Sedimentation and Biota in Malaysian Geological Records. Anjuran Persatuan Geologi Malaysia dan Jabatan Penyiasatan Kajibumi Malaysia. Ipoh, Perak, 2-4 Mac.

Ishiga, H. 1990. Paleozoic radiolarians. In Pre-Cretaceous Terranes of Japan, Osaka, disunting oleh Ichikawa, K., Mizutani, S., Hara, I., Hada, S. \& Yao, A. Publication of IGCP Project. 224. hlm. 285-295.

Jones, D.L. \& Murchey, B. 1986. Geologic significance of Paleozoic and Mesozoic radiolarian chert. Ann. Rev. Earth Planet. Sci. 14: 455-492.

Karl, S.M. 1989. Paleoenvironment implications of Alaskan siliceous deposits. Dlm Siliceous Deposits of the Tethys and Pacific Regions, disunting oleh Hein, J.R. \& Obradovic, J. New York: Springer-Verlag. hlm. 168-200.

Kuwahara, K., Yao, A. \& Yamakita, S. 1998. Reexamination of Upper Permian radiolarian biostratigraphy. Earth Science (Chikyu Kagaku) 52(5): 391-404.

Mat Niza Abdul Rahman, Saesaengseerung, D. \& Imsamut, S. 2012. Geology and stratigraphy of the Gerik Formation, Upper Perak, Malaysia. Proceedings of GEOSEA 2012. Bangkok.

Mohd Shafeea Leman. 1995. Permian ammonoids from Kuala Betis area, Kelantan and their paleogeographic significance. Bulletin of the Geological Society of Malaysia 38: 153-158.

Muhammad Ashahadi Dzulkafli, Basir Jasin \& Mohd Shafeea Leman. 2016. Taksonomi radiolaria dari genus Pseudoalbaillella berusia Perm dari Pos Blau, barat daya Kelantan, Semenanjung Malaysia. Bulletin of the Geological Society of Malaysia 62: 13-21.

Muhammad Ashahadi Dzulkafli, Basir Jasin \& Mohd Shafeea Leman. 2012. Radiolaria berusia Perm Awal (Sakmarian) dari singkapan baru di Pos Blau, Ulu Kelantan dan kepentingannya. Bulletin of the Geological Society of Malaysia 58: 67-73.

Pessagno Jr.,E.A. \& Newport, R.L. 1972.A technique for extracting radiolaria from radiolarian cherts. Micropaleontology 18(2): 231-234.

Sashida, K., Adachi, S., Igo, H., Koike, T. \& Ibrahim Amnan. 1995. Middle and Late Permian radiolarians from the Semanggol Formation, Northwest Peninsular Malaysia. Transactions and Proceedings of the Palaeontological Society of Japan, New Series 177: 43-58.

Sashida, K. \& Salyapongse, S. 2002. Permian radiolarian fauna from Thailand and their paleogeographic significance. Journal of Asian Earth Sciences 20: 691-701. 
Sashida, K. \& Tonishi, K. 1986. Upper Permian stauraxon polycystine radiolarian from Itsukaichi, western part of Tokyo Prefecture. Sci.Rep. Inst. Geosci., Univ.Tsukuba, Sec $B=$ Geol. Sci. 7: 1-13.

Spiller, F.C.P. 2002. Radiolarian Biostratigraphy of Peninsular Malaysia and Implications for Regional Palaeotectonics and Palaeogeography. Palaeontographica Abt. A. 266: 1-91.

Spiller, F.C.P. \& Metcalfe, I. 1995a. Late Palaeozoic radiolarians from the Bentong-Raub suture zones and the Semanggol Formation of Peninsular Malaysia - initial results. Journal of Southeast Asian Earth Sciences 11(3): 217-224.

Spiller, F.C.P. \& Metcalfe, I. 1995b. Palaeozoic and Mesozoic Radiolarian biostratigraphy of Peninsular Malaysia. Proc. of the IGCP Symposium on Geology of Southeast Asia and adjacent areas. Journal of Geology. Series B 5-6: 75-93.

The Malaysian and Thai Working Groups. 2014. Litho and Biostratigraphic correlations of chert beds in various rocks unit along the Malaysia-Thailand border. The MalaysiaThailand Border Joint Geological Survey Committee (MTJGSC). Geological Papers Volume 11.

The Malaysian and Thai Working Groups. 2012. Geology of The Belum-Hala transect area along the Malaysia-Thailand border. The Malaysia-Thailand Border Joint Geological Survey Committee (MT-JGSC). Geological Papers Volume 9.

Tjia, H.D. \& Syed Sheikh Almashoor. 1996. The Bentong Suture in southwest Kelantan, Peninsular Malaysia. Bulletin of the Geological Society of Malaysia 39: 195-211.
Umar Hamzah \& Ng Chiang Seng. 1995. Fosil kayu dan beberapa fosil tumbuhan dari Sungai Berok, Gua Musang Kelantan. Warta Geologi 21(4): 247.

Wang, Y.J. \& Yang, Q. 2011. Biostratigraphy, phylogeny and paleobiogeography of Carboneferous-Permian radiolarians in South China. Palaeoworld 20: 134-145.

Yao, A. \& Kuwahara, K. 2000. Permian and Triassic radiolarians from the southern Guizhou Province, China. Jour. Geosci., Osaka City Univ. 43(1): 1-19.

Zhang, N., Henderson, C.M., Xia, W.C., Wang, G.Q. \& Shang, H.J. 2010. Conodonts and radiolarians through the CisuralianGuadalupian boundary from the Pingxiang and Dachongling sections, Guangxi region, South China. Alcheringa 34: 135-160.

Program Geologi

Pusat Pengajian Sains Sekitaran dan Sumber Alam

Fakulti Sains dan Teknologi

43600 UKM Bangi, Selangor Darul Ehsan

Malaysia

*Pengarang untuk surat-menyurat; email: ashahadi@ukm.edu.my

Diserahkan: 30 Jun 2017

Diterima: 26 Oktober 2017 